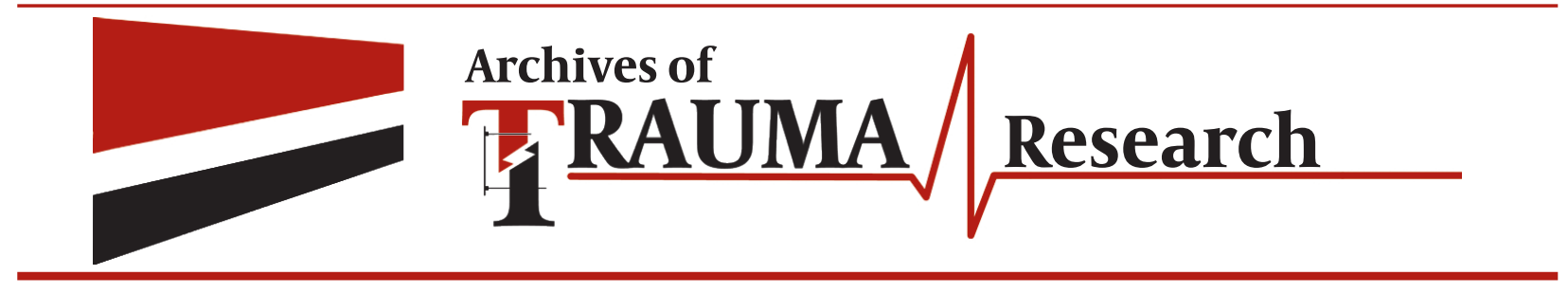

\title{
Blunt Traumatic Hernia of Diaphragm With Late Presentation
}

\author{
Abdolhossein Davoodabadi ${ }^{1}$, Esmaeil Fakharian ${ }^{1}$, Mahdi Mohammadzadeh ${ }^{1 *}$, Esmaeil Ab- \\ dorrahim Kashi ${ }^{1}$, Azadeh Sadat Mirzadeh ${ }^{2}$ \\ ${ }^{1}$ Trauma Research Center, Kashan University of Medical Sciences, Kashan, IR Iran \\ ${ }^{2}$ Student Research Center Committee, Kashan University of Medical Sciences, Kashan, IR Iran
}

\begin{tabular}{l}
\hline A R T I C L E I N F O \\
\hline Article type: \\
Research Article \\
\hline Article history: \\
Received: 05 Aug 2012 \\
Revised:10 Sep 2012 \\
Accepted: 18 Sep 2012
\end{tabular}

\begin{abstract}
A B S T R A C T
Background: Diaphragmatic hernia after blunt trauma is an uncommon and often undiagnosed condition.

objectives: We aimed to review patients who presented with delayed blunt traumatic hernia of diaphragm.

Patients and Methods: In this retrospective study, the medical records of six patients treated for blunt diaphragmatic hernias who were admitted to Kashan Shahid Beheshti hospital between June 2007 and June 2011 were analyzed.

Results: Six patients with mean age of 41 years were included in the study. Male to female ratio was 2:1. Mean duration between trauma and admission to the hospital was 6.5 years (2-26 years). Five patients had left-sided diaphragmatic hernia. Chest X-ray was obtained from all patients which was diagnostic in 50 percent of the cases $(n=4)$. Additional diagnostic imaging with computerized tomography (CT) was used in six patients and upper gastrointestinal (GI) contrast study was performed in one patient. All patients underwent thoracotomy incision. Mesh repair was utilized in one patient. The mean hospitalization time was 14.1 days. There was one postoperative death (16.7\%).

Conclusions: Late presentation of blunt diaphragmatic hernia is an uncommon and challenging situation for the surgeon. Prompt diagnosis and treatment prevent serious morbidity and mortality associated with complications such as gangrene and perforation of herniated organ.
\end{abstract}

Published by Kowsar, 2012. cc 3.0.

- Implication for health policy/practice/research/medical education:

Despite the fact that the incidence of traumatic hernia of diaphragma is uncommon, delayed diagnosis and treatment of ruptured diaphragm is associated with increased rates of morbidity and mortality.

Please cite this paper as:

Davoodabadi A, Fakharian E, Mohammadzadeh M, Abdorrahim Kashi E, Mirzadeh AS. Blunt Traumatic Diaphragmatic Hernia With Late Presentation. Arch Trauma Res. 2012:1(3): 89-92. DOI: 10.5812/atr.7593

\section{Background}

Traumatic injury to diaphragm is an uncommon condition associated with severe blunt trauma which is usually missed in the early presentation to emergency $(1,2)$. Its incidence is approximately $2 \%$ in non-penetrating trau- ma. The increasing incidence of road traffic accidents has resulted in growing its incidence despite of advanced therapeutic modalities and awareness of medical staff (3, 4). The initial diagnosis of a blunt traumatic injury to the diaphragm is generally difficult because the early clinical and radiological findings are not clear. In acute circum-

\footnotetext{
* Corresponding author: Mahdi Mohammadzadeh, Trauma Research Center, Kashan University of Medical Sciences, Kashan, IR Iran. Tel.: +98-9132632168, Fax: + 98-3615620634,E-mail:dmmzn58@gmail.com.

() 2012, Kashan University of Medical Sciences; Published by Kowsar

This is an open-access article distributed under the terms of the Creative Commons Attribution License (http://creativecommons.org/licenses/by/3.0), which permits unrestricted use, distribution, and reproduction in any medium, provided the original work is properly cited.
} 
stances, it is usually found on the table during exploratory laparotomy, although even then it may be missed (5). Nearly half of the patients remain asymptomatic and present with complications of the diseases several years after the onset of initial trauma $(4,6,7)$. Undiagnosed patients with diaphragmatic injury may present with a diverse range of complaints from abdominal discomfort to diaphragmatic tear and visceral herniation secondary to sudden increase in the intra-abdominal pressure resulting in respiratory and gastrointestinal obstruction symptoms $(8,9)$. The incidence of diaphragmatic rupture after any kind of thoraco-abdominal trauma is reported between 0.8 and 5\%, of which up to $30 \%$ present with a delay $(10,11)$. Less than $2.7 \%$ of the diaphragmatic injuries were detected before four months from the initial damage (8). Inaccurate interpretation of the imaging studies or intermittent and trivial symptoms of the hernia are main reasons for missed diagnosis $(12,13)$.

\section{Objectives}

Clinical presentation and management of 6 cases of delayed blunt traumatic hernia of diaphragm were discussed to highlight challenges in diagnosis and handling of complications.

\section{Patients and Methods}

Six patients with the diagnosis of delayed blunt traumatic hernia of diaphragm treated in Kashan Shahid Beheshti university hospital between June 2007 and June 2011 were enrolled to this study. The mechanism, duration of complaints, clinical presentation, site of injury, kind of visceral herniation, surgical repair, and outcome of the patients have been scrutinized. Diaphragmatic hernia repair and organ reduction were performed in all patients through thoracic approach.

\section{Results}

Mean age $( \pm S D)$ of the patients was 41 years $( \pm 15)$ (rang ing from 25 to 67 years), with a male to female ratio of 2:1. The mean duration between the incident and admission to the hospital was 6.5 years (ranging from 2 to 26 years). All of the patients were victims of car accident. Five out of six patients were affected by left and one by right diaphragmatic hernias. All of the patients suffered from abdominal pain and two patients were admitted with the symptoms of intestinal obstruction. Four patients demonstrated respiratory symptoms, including dyspnea. Chest X-ray was performed for all patients as the initial diagnostic imaging work up. It was diagnostic in 3 patients and showed small bowel and colon loops in hemithorax, while it was recorded as atypical in the other 3 cases including 2 cases of lung empyema and diaphragmatic dome elevation in the last case. Both thoracic CT scan and barium study were diagnostic in all patients (Figure 1). Barium study (lateral view) shows that the stomach

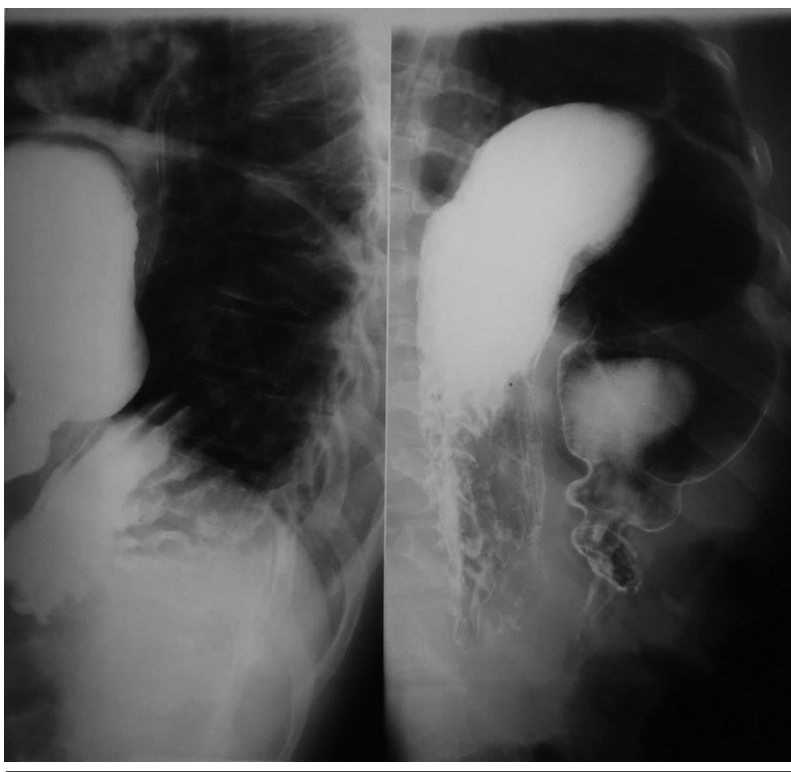

Figure 1. Upper Gastrointestinal (GI) Contrast Study of a Patient Presented With Intermittent Abdominal Pain, Vomiting, and Dyspnea, Especially after Heavy Meal, 26 Years from Car Accident

Table 1. Demographic Features, Clinical Findings, Diagnosis, and Management of Patients

\begin{tabular}{|c|c|}
\hline & Variants \\
\hline Number , No. & 6 \\
\hline Age, Mean & 41 \\
\hline Gender, Male: Female & $4: 2$ \\
\hline Time between operation and trauma, $y$ & 6.5 \\
\hline Hospitalization time ,d, Mean & 14.1 \\
\hline \multicolumn{2}{|l|}{ Presenting symptoms } \\
\hline Abdomen pain & 6 \\
\hline Dyspnea & 3 \\
\hline Vomiting & 3 \\
\hline Fever & 2 \\
\hline Localization, Left: Right & $5: 1$ \\
\hline Diameter, cm, Mean & 11.6 \\
\hline \multicolumn{2}{|l|}{ Chest X-ray } \\
\hline Diagnostic & 3 \\
\hline Atypical & 3 \\
\hline \multicolumn{2}{|l|}{ Herniated organ } \\
\hline Stomach & 4 \\
\hline Transverse colon & 3 \\
\hline Omentum & 2 \\
\hline Small bowel & 1 \\
\hline Liver & 2 \\
\hline Spleen & 1 \\
\hline
\end{tabular}


lies in left hemithorax (Figure 1). The most common herniated organ was stomach $(n=4)$. Transverse colon was herniated in 3 and liver in 2 patients. Two patients needed herniated organ resection due to micro-perforation and necrosis. The mean diameter of defect in the diaphragm after reduction was $11.1 \mathrm{~cm}$ (range: $6-16 \mathrm{~cm}$ ). Primary repair was used in 5 patients and Prolene mesh in 1 patient. Mean hospitalization time was 14.1 days ( \pm 3.4 days). There was one postoperative death (16.7\%), a 67 year-old man with history of car accident 2 years before operation who was admitted with abdominal pain, vomiting, and respiratory septic features (fever, tachycardia, tachypnea). The patient underwent left posterlateral thoracotomy with the diagnosis of thoracic empyma due to diaphragmatic herniation, and stomach torsion and gangrene. He died 2 days after the operation. Other patients were discharged without any complication (Table 1).

\section{Discussion}

Early diagnosis of diaphragmatic injury is difficult and often delayed. It was detected in $1.3 \%$ of the patients in the acute phase with an Injury Severity Score (ISS) of $>15$ upon admission to a trauma center. Approximately half of the cases had herniated tissues through the diaphragmatic tear (12). Sudden intra-abdominal pressure changes may produce diaphragmatic injury, either as a laceration or an avulsion (2). The rupture typically originates at the central tendineum or musculotendinous junction. Although the natural history of the diaphragmatic injury is unknown, some animal studies have shown that it might heal without development of hernia $(14,15)$. If diagnosis of the injury is missed after the first admission, patients may be asymptomatic or have intermittent chronic abdominal or respiratory symptoms due to increased intra-abdominal pressure including constipation, cough, or distension after heavy meal. Sudden increased intra-abdominal pressure may lead to herniation and obstruction of hollow organs complicating with strangulation and/or perforation of the herniated contents (16). Approximately $84 \%$ of all hernias were on the left side similar to the previous studies (16-18) possibly due to relative weakness of left hemi-diaphragm and protective effect of liver on right diaphragm. Diaphragmatic herniation with blunt trauma was more common in left hemi-diaphragm (12). In the present study, the only patient with right-sided diaphragmatic hernia was a 43-year-old female with a history of blunt trauma 5 years before admission. The patient was manifested by symptoms of chronic dyspnea and epigastric pain. During the operation, a diaphragmatic defect of $15 \mathrm{~cm}$ was detected through which right lobe of liver was herniated. Primary repair of diaphragm was performed to restore the defect. The mean interval between the trauma and operation was almost similar to that in previous studies. It was 6.5 years in our study, 5.9 years in Okan et al. (16) and 4.1 years in Reber et al. (17) studies. In Feliciano et al. (18) study, this time was 1 year, but it is noteworthy that their study was performed on diaphragmatic hernia after penetrating injuries. Except for a patient who showed chronic symptoms due to liver herniation through right hemidiaphragm, other patients were admitted to the hospital with acute problems such acute abdomen and respiratory insufficiency that mandated urgent operative intervention. The initial chest X-ray was diagnostic only in $25 \%$ of patients where hemopneumothorax was visible in the thoracic cavity in acute setting of the injury (12). Similar to Reber et al. (17) and Worthy et al. (19), chest X-ray, as an initial imaging, was diagnostic in 50 percent of the patients. Although Okan et al. reported a higher percentage of diagnostic value for chest X-ray (up to 80\%), they used the additional diagnostic tests because most of their patients had chronic and long-term complaints (16). In recent studies CT scan and MRI were used for additional imaging $(16,20,21)$, while upper gastrointestinal (GI) contrast studies were used in earlier case reports (22). In the acute phase of diaphragmatic injury, CT scan is able to add $10 \%$ to the preoperative diagnostic value of chest Xray (12). In delayed presentation, each of the CT scan and barium study was 100\% diagnostic for diaphragmatic hernia detection in our study. Orkan et al., as well, reported that CT scan and MRI findings were $100 \%$ diagnostic in both penetrating and blunt mechanisms (16). Bodanapally et al. with the use of multi-detector CT scanning reported promising results in penetrating diaphragmatic injuries, with sensitivity, specificity, and accuracy rates of $87 \%, 72 \%$, and $77 \%$, respectively (23). Therefore, computed tomography is the diagnostic test of choice in suspected patients with diaphragmatic hernia. Similar to the previous case series $(17,18,22)$, the preferred method of defect closure in our series was primary repair using interrupted non-absorbable sutures. Although in Orkan et al. study (16) the mean diameter of defect size and mean interval time between trauma and operation were less than those in our study. Orkan et al. used prosthetic material as a preferred method of defect closure. They explained that the mesh was used because defect size and the duration might cause loss of elasticity of the diaphragm. Stomach was the most common herniated organ in the present study. Since the most diaphragmatic injury occurred in left diaphragm, stomach could be considered as the most common herniated organ. Gastric volvulus associated with traumatic diaphragmatic hernia was relatively rare and made the diagnosis even more difficult (24-26). Stomach resection was performed in 2 patients due to micro-perforation and necrosis. During recent decades, advanced diagnostic modalities and postoperative management lead to decreasing mortality rates due to delayed diagnosis of diaphragmatic herniation from $25 \%$ to $10 \%$ $(17,22)$. However, the presence of strangulation with gangrene and perforation was related to increased morbidity and mortality. Mortality rate of undergone emergency repairs in this condition was up to $32 \%$ (27). There was one 
postoperative death in our study due to gastric torsion and gangrene (16.7\%). Although most authors granted trans-abdominal approach to repair defects in acute injuries due to high incidence of associated abdominal injuries in this setting $(12,28)$, the definite treatment of blunt traumatic hernia of diaphragm was surgical repair with standard posterlateral thoracotomy and reduction of herniated organs into abdominal cavity first, and then repair of injured diaphragm. This approach allowed the surgeon to release strong adhesions between herniated viscera and pleura, and achieve complete clearance of pleural cavity and repair of diaphragmatic defect. While this approach may require additional laparotomy if small or large bowel has to be resected, nevertheless in our study, no patient needed to undergo laparotomy. Except for one patient who died after the operation due to critical situation (sepsis and stomach gangrene), others were discharged without any complication. In conclusion, delayed diagnosis and treatment of ruptured diaphragm are associated with increased rates of morbidity and mortality and necessitates early aggressive surgical intervention. Despite the fact that the incidence of diaphragmatic hernia is uncommon, it should be suspected in patients with gastro-intestinal complains and history of recent chest blunt trauma.

\section{Acknowledgments}

The authors would like to thank the operating room personnel in Kashan Shahid Beheshti hospital for their assistance in data collection.

\section{Authors' Contribution}

Abdolhossein Davoodabadi (study manager and study designer), Esmaeil Fakharian (article writing), Mahdi Mohammadzadeh (study design and article writing), Esmaeil Abdorrahim Kashi (data collection ), Azadeh Sadat Mirzadeh (data analysis ).

\section{Financial Disclosure}

None declared.

\section{Funding/Support}

None declared.

\section{References}

1. Adler DH. Blunt diaphragmatic injury in a 7-year-old girl1 1 Clinical Communications (Pediatric) is coordinated by Roger Barkin, MD, of HealthONE, Denver, Colorado, and Ghazala Sharieff, MD of the University of Florida, Jacksonville, Florida. J Emerg Med. 2002;23(1):39-42.

2. Edino S, Alhassan S, Ajayi O. Traumatic diaphragmatic rupture with gastro-pleuro-cutaneous fistula: A case report and literature review. Nigerian J Surg. 2002;8:18-20.

3. Chughtai T, Ali S, Sharkey P, Lins M, Rizoli S. Update on managing diaphragmatic rupture in blunt trauma: a review of 208 consecutive cases. Can J Surg. 2009;52(3):177-81.

4. Galimberti A, Casagrande A, Compagnoni BM, Sansonetti G, Rus- coni A, Grassi M, et al. [Late post-traumatic diaphragmatic hernia: unusual cause of colonic occlusion]. Chir Ital. 2001;53(4):551

5. Clarke DL, Greatorex B, Oosthuizen GV, Muckart DJ. The spectrum of diaphragmatic injury in a busy metropolitan surgical service. Injury. 2009;40(9):932-7.

6. Fibla J, Gómez G, Farina C, Penagos J, Estrada G, León C. Corrección de una hernia diafragmática por vía torácica. Cir Esp. 2003;74:242-4

7. Schiano di Visconte M, Picciano P, Munegato G. [Acute abdomen due to a right-sided strangulated traumatic diaphragmatic hernia. Case report]. Minerva Chir. 2006;61(5):451-4.

8. Shreck GL, Toalson TW. Delayed presentation of traumatic rupture of the diaphragm. J Okla State Med Assoc. 2003;96(4):181-3.

9. Disler DG, Deluca SA. Traumatic rupture of the diaphragm and herniation of the liver. Am Fam Physician. 1992;46(2):453-6.

10. Rossetti G, Brusciano L, Maffettone V, Napolitano V, Sciaudone G, Del Genio G, et al. Giant right post-traumatic diaphragmatic hernia: laparoscopic repair without a mesh. Chir Ital. 2005;57(2):243 6.

11. Pappas-Gogos G, Karfis EA, Kakadellis J, Tsimoyiannis EC. Intrathoracic cancer of the splenic flexure. Hernia. 2007;11(3):257-9.

12. Hanna WC, Ferri LE, Fata P, Razek T, Mulder DS. The current status of traumatic diaphragmatic injury: lessons learned from $105 \mathrm{pa}$ tients over 13 years. Ann Thorac Surg. 2008;85(3):1044-8.

13. De Blasio R, Maione P, Avallone U, Rossi M, Pigna F, Napolitano C. [Late posttraumatic diaphragmatic hernia. A clinical case report]. Minerva Chir.1994;49(5):481-7.

14. Gamblin TC, Wall CEJ, Morgan JH, Erickson DJ, Dalton ML, Ashley DW. The Natural History of Untreated Penetrating Diaphragm Injury: An Animal Model.J Trauma Acute Care Surg. 2004;57(5):98992.

15. Zierold D, Perlstein J, Weidman ER, Wiedeman JE. Penetrating trauma to the diaphragm: natural history and ultrasonographic characteristics of untreated injury in a pig model. Arch Surg. 2001;136(1):32-7.

16. Okan I, Bas G, Ziyade S, Alimoglu O, Eryilmaz R, Guzey D, et al. Delayed presentation of posttraumatic diaphragmatic hernia. Ulus Travma Acil Cerrahi Derg. 2011;17(5):435-9.

17. Reber PU, Schmied B, Seiler CA, Baer HU, Patel AG, Buchler MW. Missed Diaphragmatic Injuries and Their Long-Term Sequelae. Trauma Acute Care Surg. 1998;44(1):183-88.

18. Feliciano DV, Cruse PA, Mattox KL, Bitondo CG, Burch JM, Noon GP, et al. Delayed Diagnosis of Injuries to the Diaphragm after Penetrating Wounds. JTrauma Acute Care Surg. 1988;28(8):1135-44

19. Worthy SA, Kang EY, Hartman TE, Kwong JS, Mayo JR, Muller NL. Diaphragmatic rupture: CT findings in 11 patients. Radiology. 1995;194(3):885-8.

20. Walchalk LR, Stanfield SC. Delayed presentation of traumatic diaphragmatic rupture. J Emerg Med. 2010;39(1):21-4.

21. Eren S, Kantarci M, Okur A. Imaging of diaphragmatic rupture after trauma. Clin Radiol.2006;61(6):467-77.

22. Hegarty MM, Bryer JV, Angorn IB, Baker LW. Delayed presentation of traumatic diaphragmatic hernia. Ann Surg. 1978;188(2):229-33.

23. Bodanapally UK, Shanmuganathan K, Mirvis SE, Sliker CW, Fleiter TR, Sarada K, et al. MDCT diagnosis of penetrating diaphragm injury. Eur Radiol. 2009;19(8):1875-81.

24. Bemelman WA, van Baal JG, Keeman JN. Volvulus of the stomach after traumatic hernia diaphragmatica. Neth J Surg. 1989;41(1):8 10.

25. Borsari A, Villa EM, Caleffi A, Poletti G, Ambrosino A. [Post-traumatic intrathoracic gastric volvulus. Presentation of a clinical case]. Minerva Chir. 1989;44(21):2275-9.

26. Wastell C, Ellis H. Volvulus of the stomach. A review with a report of 8 cases. Br J Surg. 1971;58(8):557-62.

27. Haciibrahimoglu G, Solak O, Olcmen A, Bedirhan MA, Solmazer $\mathrm{N}$, Gurses A. Management of traumatic diaphragmatic rupture. Surg Today. 2004;34(2):111-4.

28. Murray JA, Demetriades D, Asensio JA, Cornwell EE, Velmahos GC, Belzberg H, et al. Occult injuries to the diaphragm: prospective evaluation of laparoscopy in penetrating injuries to the left lower chest. J American College Surg. 1998;187(6):626-30. 